\title{
Impelementasi Model Waterfall pada Media Pembelajaran Pengenalan Angka dan Huruf Berbasis Android
}

\author{
Sidik $^{1}$, Muhammad Fajar Syahroni ${ }^{2}$ \\ ${ }^{1,2}$ Sekolah Tinggi Manajemen Informatika dan Komputer Nusa Mandiri \\ e-mail: sidik.sdk@nusamandiri.ac.id,muhamadfajarsyahroni@gmail.com
}

\begin{abstract}
The era of globalization, information technology is advancing rapidly, one of which is the development of interactive animation. Interactive animation technology is now widely used in various industries, such as advertising, education, tourism, entertainment, and so on. In the world of education, interactive animation can be applied as an effective learning medium. In the preparation of this study, the authors used the Waterfall model to design the system and to design learning media using Adobe Flash Professional CS6 which is considered very suitable in making interactive animation-based learning media. The Waterfall Model, is the most familiar system model and is widely used in designing interactive animation-based applications. In making interactive animation-based learning media can increase learning interest and students' attention to the introduction of numbers and letters and kinds of sounds and images. In addition, students can also learn while playing and train to recognize numbers and letters, with varied images. Respondents in this study consisted of teachers and students. The results of this study $80 \%$ stated that this learning media was easy to use, $90 \%$ said that respondents liked the application of media learning to recognize numbers and letters based on interactive animation, 70\% of respondents said they learned to recognize numbers and letters that were fun. Besides this interactive animation-based learning media helps train students to recognize numbers and letters, with diverse images, and can also facilitate teachers in training students at school.
\end{abstract}

Keywords - media, learning, multimedia, animation, interactive, letters, numbers

\section{PENDAHULUAN}

Pendidikan merupakan suatu hal yang sangat diutamakan dalam aspek kehidupan terlebih jika dimulai pada usai dini. Untuk menciptakan generasi yang berkualitas, masyarakat sangat mengharapkan adanya pendidikan yang memadai untuk putraputrinya, terlebih pada saat mereka masih berada dalam tataran usia dini (Ridho, Markhamah, \& Darsinah, 2015). Usia dini merupakan usia yang sangat penting bagi perkembangan anak sehingga disebut golden age (lima tahun pertama). Anak usia dini sedang dalam tahap pertumbuhan dan perkembangan yang paling pesat, baik fisik maupun mental. Salah satu kemampuan yang terpenting dan harus dikuasai oleh anak-anak adalah kemampuan membaca dan menulis. Pendidikan adalah salah satu media dalam membentuk kepribadian seorang individu. Dalam dunia pendidikan merupakan sarana belajar bagaimana mengetahui sebuah pengetahuan yang baru dan diajarkan bagaimana caranya memilah-milah sesuatu yang salah dan yang benar. Dengan pendidikan, diharapkan dapat menciptakan sumber daya manusia yang kompeten dan berkualitas sangat dibutuhkan dalam upaya mendukung produktivitas dan aktivitas agar tujuan negara dapat tercapai dengan sempurna (Setiani,Dewi,Santoso Sigit, 2016). Dalam dunia pendidikan suatu metode pembelajaran dapat dihadirkan dengan menggunakan alat peraga pembelajaran atau sering dikenal dengan media pembelajaran (Wiyarti \& Nugroho, 2013). Pembelajaran mengandung lima komponen komunikasi, yaitu guru (komunikator), bahan pembelajaran, media pembelajaran, peserta didik (komunikan), dan tujuan pembelajaran. Jadi, media pembelajaran adalah segala sesuatu yang dapat digunakan untuk menyalurkan pesan (bahan pembelajaran) sehingga dapat merangsang perhatian, minat, pikiran dan perasaan peserta didik dalam kegiatan belajar mengajar untuk mencapai tujuan pembelajaran (Khasanah, 2013).

Pengetahuan logika matematika dibangun ketika anak bermain atau memanipulasi material atau benda-benda yang ada di sekitarnya. Selain itu interaksi anak dengan orang dewasa juga bisa membangun pengetahuan ini. Ketika seorang dewasa membimbing, bertanya, memberi respon, bereaksi terhadap anak saat mereka memanipulasi objek, keinginan untuk belajar logika matematika akan muncul. Kemampuan anak berkaitan dengan logika matematika dapat ditingkatkan sejak usia dini sedangkan peran orang tua dalam hal ini juga sangat penting memberikan dukungan dan semangat kepada putra putrinya (Kurnianingtyas \& Nugroho, 2012). Perkembangan teknologi informasi telah membawa 
pada tahapan pengalaman yang tidak pernah diperkirakan sebelumnya. Salah satu cara yang cukup diminati oleh guru adalah mengajar menggunakan komputer. Komputer dapat meningkatkan minat anak dan menggugah rasa ingin tahu serta dapat membuat pembelajaran menjadi menyenangkan.

Salah satu model pembelajaran yang dapat meningkatkan minat belajar siswa dalam belajar adalah model pembelajaran kooperatif (cooperatif learning). Model pembelajaran ini menekankan siswa saling bekerja sama dalam kelompoknya. Terutama pada pelajaran menghitung, karena pelajaran ini cukup sulit dan juga membutuhkan konsentrasi yang penuh agar siswa-siswi dapat mengerti. Penyampaian metode pembelajaran yang selama ini digunakan masih menggunakan cara konvensional atau tatap muka (Yuniati, Purnama, \& Nugroho, 2012). Dengan demikian dirasakan masih memiliki banyak kekurangan dalam menyampaikan pembelajaran ke siswa, antara lain dalam proses belajar siswa diminta menghafal kosakata atau angka (Lestari, 2014). Selain itu materi yang di sampaikan tidak dapat di serap dengan baik karena media yang di gunakan oleh guru kurang menarik (Waskito, 2017). Ketika hal ini terjadi pada tahap pembelajaran dasar siswa akan mengalami kesulitan mengikuti materi-materi pembelajaran selanjutnya. Setelah di lakukan observasi, dan berdasarkan hasil diskusi dengan guru di Sekolah Taman KanakKanak Salsabilla dapat di simpulkan bahwa banyak siswa yang tidak fokus untuk belajar di karenakan cara belajarnya kurang menarik sehingga menimbulkan rasa bosan dan jenuh terhadap siswa. Setelah peneliti melakukan observasi awal di Pendididkan Taman Kanak-Kanak Salsabilla, peneliti menemukan masalah bahwa anak sudah bisa menyebutkan urutan pada angka tetapi dalam hal berhitung sebagian besar siswa masih belum bisa. Penulis juga menemukan masalah yaitu media yang digunakan guru dalam pengenalan angka kepada anak hanya melalui kartu-kartu angka danbmelalui papan tulis, sehingga anak kurang tertarik dengan apa yang disampaikan oleh guru. Bentuk pembelajaran konvensional siswa terkesan pasif dan guru bersifat aktif, siswa kurang diberi kesempatan untuk berinisiatif mencari jawaban sendiri serta menerapkan rumus. Sehingga mempengaruhi prestasi belajar siswa (Sidik, 2017).

Berdasarkan batasan masalah di atas, maka dapat dirumuskan permasalahannya sebagai berikut: Bagaimana cara pembelajaran menghitung utuk anak usia dini, dengan menggunakan rancangan animasi?. Dengan menggunakan media ini, penulis ingin memperkenalkan kepada anak cara belajar menggunakan media pembelajaran interaktif melalui komputer yang dilengkapi dengan animasi, audio visual, fungsi tombol. Sehingga media belajar ini dapat menarik minat belajar anak dalam mengenal angka dan huruf. Diperlukan juga adanya pendampingan dari orang tua maupun guru selama anak belajar menggunakan media belajar ini.

Berdasarkan latar belakang permasalahan, maka penulis menyusun maksud dalam penelitian ini yaitu:

1. Memudahkan siswa dalam memahami menghitung sejak usia dini khususnya pada Sekolah Taman Kanak-Kanak Salsabila

2. Membantu pihak pengajar dalam menyampaikan materi pelajaran dengan interface yang lebih menarik dari sekedar membaca buku dan ceramah.

Adapun tujuan dalam penulisan artikel ilmiah ini adalah membangun sebuah media pembelajaran dalam bentuk animasi interaktif mengenai angka dan huruf agar dapat mempermudah proses belajar siswa.

\section{METODOLOGI PENELITIAN}

Metode penelitian yang digunakan pada penulisan ini adalah metode kualitatif dengan pendekatan deskriptif yang dilengkapi dengan penelitian menggunakan kuesioner dan wawancara kepada responden yang sudah ditentukan sebelumnya. Untuk melengkapi metode penelitiannya, penulis menambahkan metode pengumpulan data dan model pengembangan sistem.

\section{A. Metode Pengumpulan data}

Metode penelitian yang di gunakan dalam penyusunan penelitian ini adalah :

1. Observasi Dengan melakukan pencatatan, pengumpulan data yang di butuhkan dan melakukan pengamatan langsung ke Sekolah Taman Kanak-Kanak salsabila untuk mengamati proses belajar pada sekolah tersebut.

2. Wawancara Wawancara merupakan percakapan antar dua orang atau lebih dan berlangsung antara narasumber dan pewancara. Dalam hal ini penulis mewawancarai dengan mengajukan beberapa pertanyaan kepada guru ibu Vera Prihatini Sekolah Taman Kanak-Kanak Salsabilla.

3. Studi pustaka Dalam penyusunan penelitian ini, penulis menggunakan beberapa literatur yang berhubungan dengan mempelajari buku-buku, jurnal, artikel-artikel internet dan bahan pustaka lainnya.

\section{B. Model Pengembangan Sistem}

Model pengembangan sistem yang digunakan pada penulisan ini adalah Model Waterfall. Tahapan pengembangan sistem yang terdapat pada model ini terdiri dari:

1. Analisa Kebutuhan Sistem 
Kebutuhan sistem yang digunakan dalam membuat animasi interaktif pembelajaran matematika dasar adalah difungsikan sebagai proses belajar pengenalan aturan menghitung yang baik dan benar secara interaktif sehingga siswa tidak bosan untuk belajar. Pada media pembelajaran ini, pengguna dapat dengan mudah dalam menggunakan aplikasinya karena dilengkapi dengan panduan cara menggunakan media pembelajaran tersebut.

2. Desain

Ditahap ini penulis akan menspesifikasikan mengenai arsitektur media pembelajaran, gaya, tampilan dan kebutuhan material atau bahan untuk program. Karakteristik software antara lain format, scenario, Roles, Decisions, scoreModel, Indicators dan symbol.

3. Code Generation

Pada penelitian ini, penulis menggunakan teknik pemrograman terstruktur agar aplikasi dapat digunakan secara mudah dan terurut.

4. Testing

Proses pengujian yang digunakan dalam membuat animasi interaktif media pembelajaran menghitung dan membaca ini menggunakan teknik pengujian white box untuk menguji struktur perancangan dari animasi

\section{HASIL DAN PEMBAHASAN}

\section{A. Analisis Kebutuhan Sistem}

Media pembelajaran berbasis animasi interaktif ini merupakan sebuah aplikasi yang mudah digunakan dan menarik bagi pengguna. Pengguna (user) dapat langsung menjalankan aplikasi media pembelajaran ini dengan menekan dua kali ikon pada desktop maka aplikasi ini akan terbuka. Berikut spesifikasi kebutuhan sistem dari media pembelajaran angka dan huruf berbasis animasi interaktif.

Halaman menu utama, tediri dari:
a. Menu Angka,
b. Menu Huruf,
c. Menu Berhitung,
d. Menu Membaca,
e. Menu Latihan,
f. Menu Bermain, dan
g. Menu Profil

Jika pengguna akan menutup aplikasi ini, maka dapat dilakukan dengan menekan tanda silang yang ada di pojok kanan atas.
B. Desain
1. Desain User Interface
a. Tampilan Opening

Pada halaman ini menunjukan tampilan awal dari aplikasi media pembelajaran angka dan huruf yang disertai animasi gambar dan suara yang sesuai.

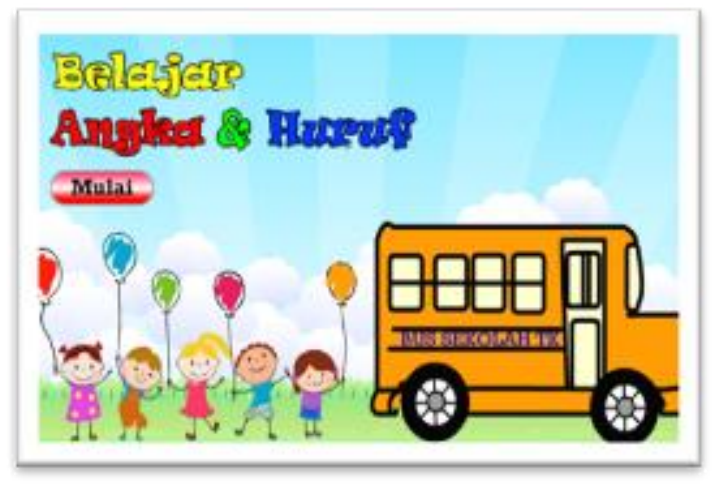

Gambar.1. Tampilan Opening

b. Tampilan Menu Utama

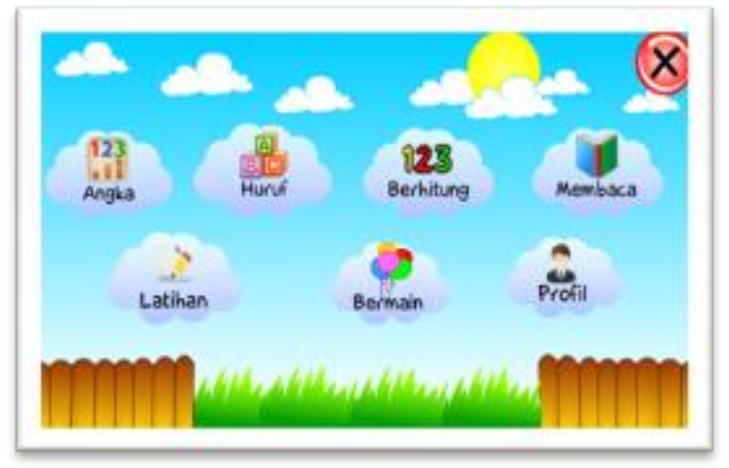

Gambar 2. Tampilan Menu Utama

Pada user interface ini terdapat delapan tombol navigasi yang dapat digunakan oleh user yang terdiri dari tombol Angka, Huruf, Berhitung, Membaca, Latihan, Bermain, Profil dan tombol X untuk kelar aplikasi animasi interaktif.

c. Tampilan Menu Angka

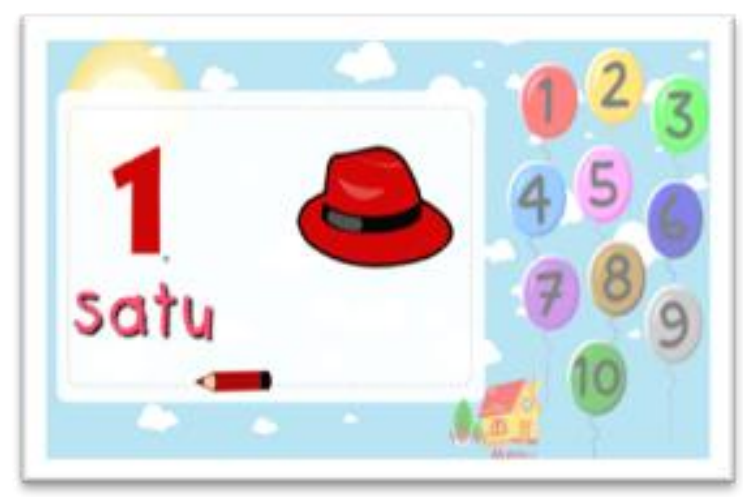

Gambar 3. Tampilan Menu Angka

d. Tampilan Menu Huruf

Pada halaman ini menunjukan tampilan papan huruf dari aplikasi media pembelajaran yang digunakan sebagai alat bantu bagi pengguna. 


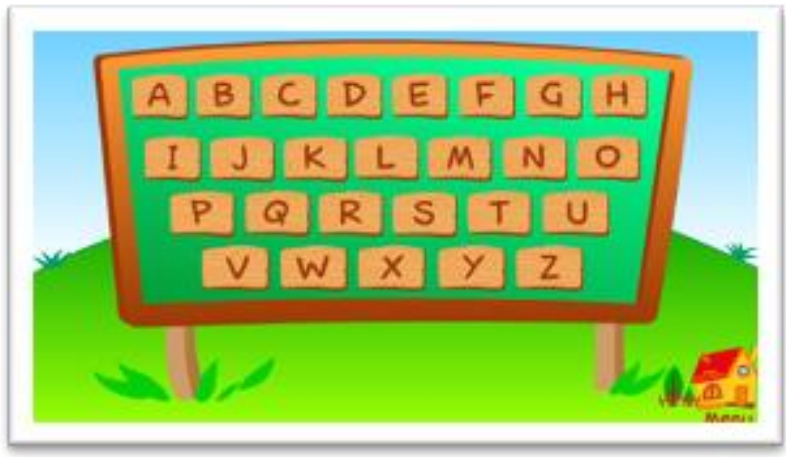

Gambar 4. Tampilan Menu Huruf

Pada halaman ini akan di tampilkan daftar huruf yang digambarkan seperti menyerupai keyboard yang akan memudahkan siswa/siswi untuk memilih macam-macam huruf yang akan di gunakan.

\section{e. Tampilan Menu Berhitung}

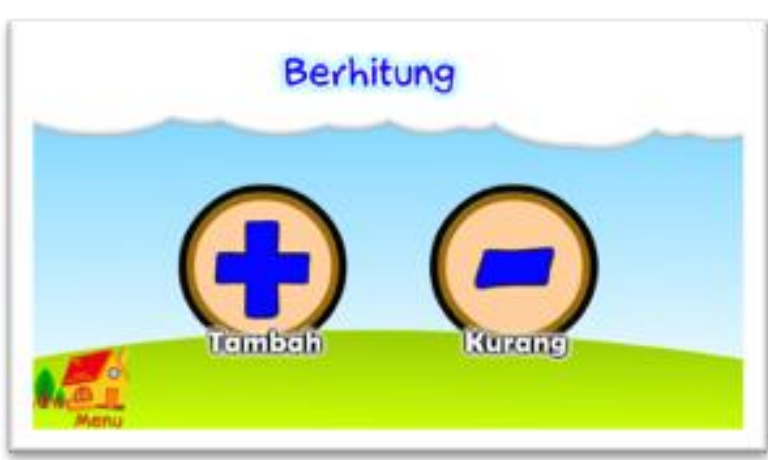

Gambar 5. Tampilan Menu Berhitung

Pada halaman ini terdapat dua tombol navigasi yang ditandai dengan simbol "+" untuk penjumlahan dan simbol "_" untuk pengurangan yang disertai gambar dan suara.

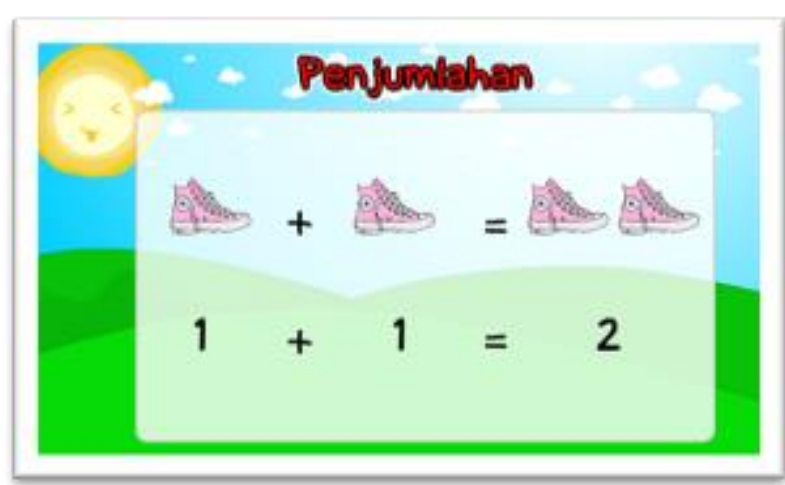

Gambar 6. Tampilan menu Penjumlahan

Pada halaman ini terdapat beberapa contoh perhitungan yang disertai aneka gambar dan suara yang lucu dan menarik.

\section{f. Tampilan Menu Mambaca}

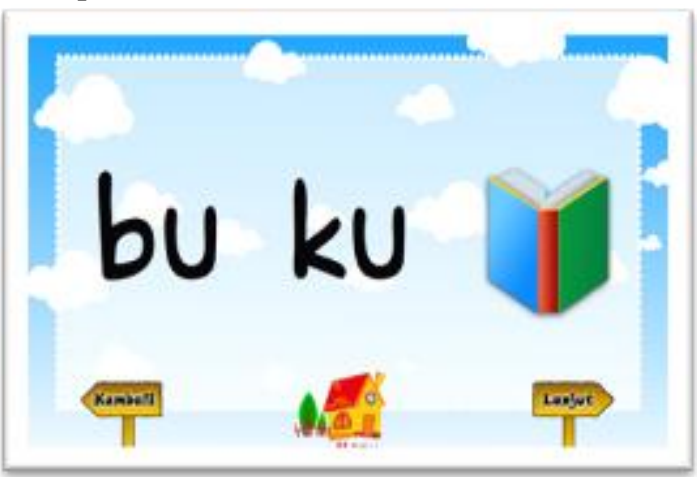

Gambar 7. Tampilan Menu Membaca

Pada halaman ini akan ditampilkan beberapa kata yang di bagi menjadi dua suku kata untuk memudahkan dalam pembacaan.

g. Tampilan Menu Latihan

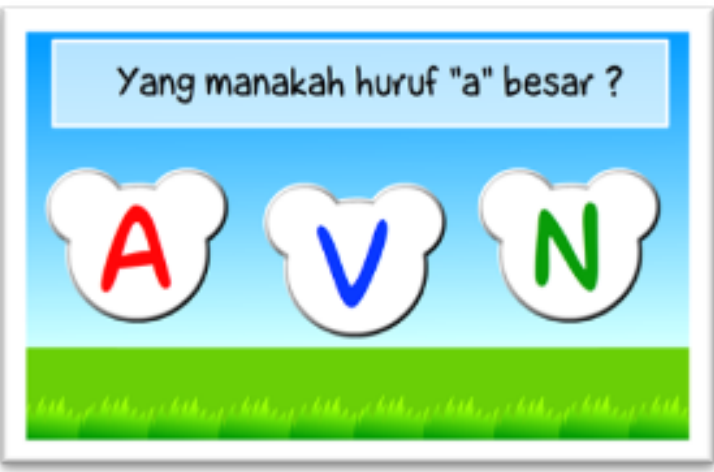

Gambar 8. Tampilan Menu Latihan

Pada halaman ini akan ditampilkan beberapa huuf dengan kombinasi warna yang berbeda, kemudian siswa/siswi di minta untuk memilih huruf yang sesuai dengan pertanyaan yang di ajukan.

\section{State Transition Diagram}

a. Menu Utama

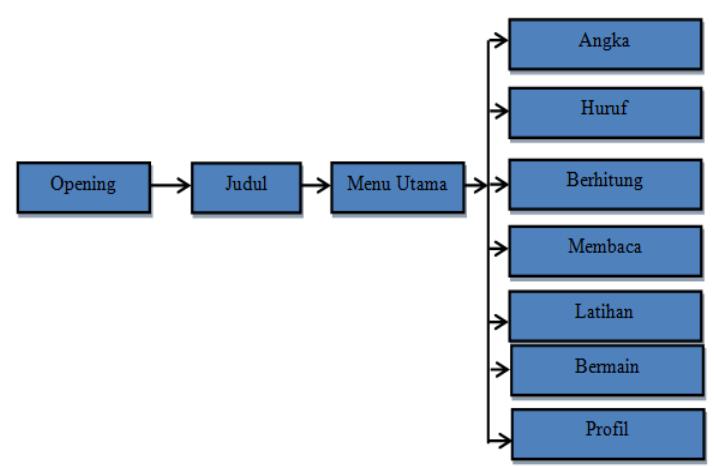

Gambar 9. State Transition Diagram Menu Utama 
Menggambarkan menu awal dimana pertama kali user akan menemui opening dengan judul belajar angka dan huruf, lalu ke menu utama yang terdapat tombol mengenal angka, huruf, berhitung, membaca, latihan, bermain, dan profil.

b. Menu Angka

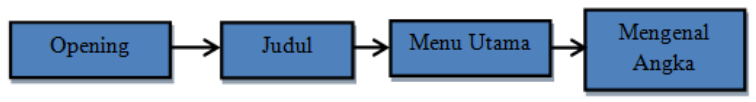

\section{Gambar 10. State Transition Diagram Menu Angka}

Dalam scane ini nama bagian-bagian dalam mengenal angka maka user harus memilih tombol yang ada, adapun tombol pilihan nya adalah menu angka yang di dalamnya masing-masing terdapat media suara dan gambar.

\section{c. Menu Huruf}

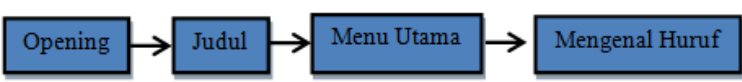

\section{Gambar 11. State Transition Diagram Menu Huruf}

Dalam scane ini nama bagian-bagian dalam mengenal huruf maka user harus memilih tombol yang ada.

d. Menu Berhitung

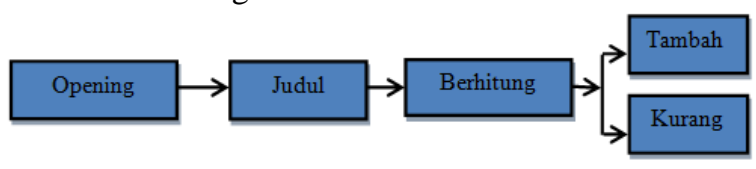

Gambar 12. State Transition Diagram Menu Berhitung

Pada scene ini digambarkan mengenai menu berhitung, dan terdapat dua tombol pilihan menu berhitung diantanya menu tambah dan menu kurang. Pada menu tambah dan menu kurang terdapat gambar serta angka. Dimana gambar serta angka itu terdapat penjumlahan atau pengurangan serta terdapat hasil dari penjumlahan atau pengurangan tersebut.

e. Menu Membaca

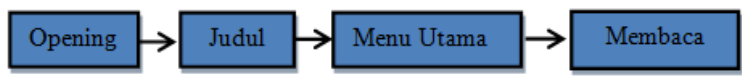

Gambar 13. State Transition Diagram Menu Membaca

Dalam scane ini menampilkan beberapa huruf abjad dengan media suara dan contoh kata, agar melatih user membaca. f. Menu Latihan

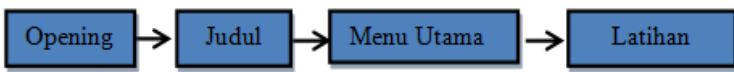

Gambar 14. State Transition Diagram Menu Latihan

C. Code Generation

Media pembelajaran angka dan huruf berbasis animasi interaktif ini dirancang dengan menggunakan konsep pemograman terstruktur dan terurut sehingga memudahkan user dalam menggunakannya.

\section{Pengujian (Testing)}

\section{Pengujian White Box}

Dengan menggunakan metode pengujian White Box, rekayasa sistem dapat melakukan test case yang dapat :

a. Memberikan jaminan bahwa semua jalur independen pada suatu modul telah digunakan paling tidak satu kali.

b. Menggunakan semua keputusan logis pada sisi true dan false.

c. Mengeksekusi semua loop (perulangan) pada batasan mereka dan pada batas operasional pengguna aplikasi.

Dibawah ini diambil contoh diagram alir (flowchart) untuk menu latihan.

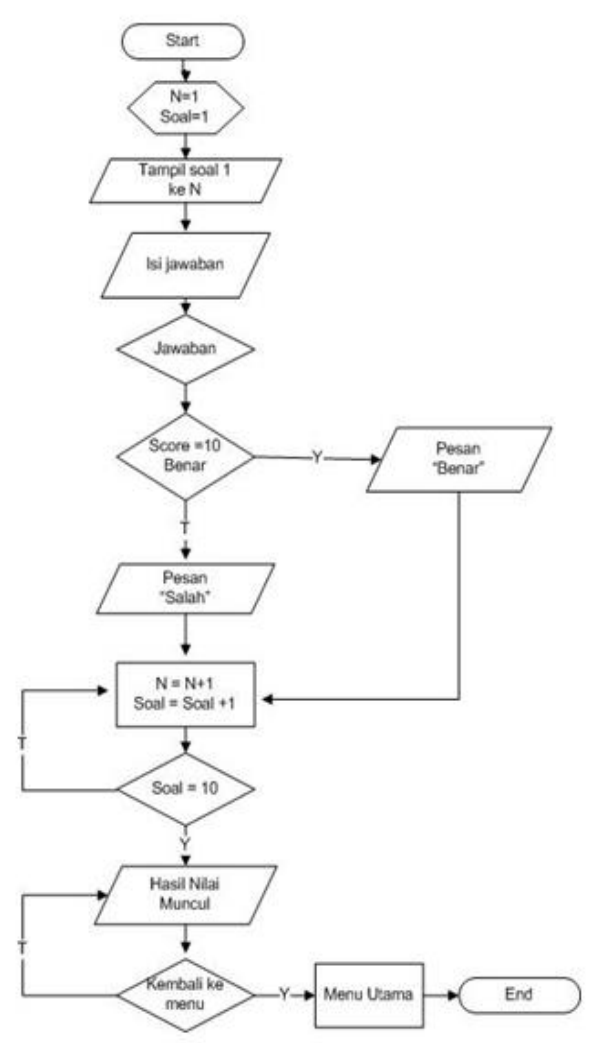

Gambar 15. Diagram alir menu latihan 
Kompleksitas Siklomatis (pengukuran kuantitatif terhadap kompleksitas logis suatu program) dari grafik alir dapat diperoleh dengan perhitungan :

$$
\mathbf{V}(\mathbf{G})=\mathbf{E}-\mathbf{N}+\mathbf{2}
$$

Keterangan :

$\mathrm{E}=$ Jumlah $e$ dge grafik yang ditandai dengan tanda panah

$\mathrm{N}=$ Jumlah simpul grafik alir yang ditandai dengan gambar lingkaran.

Sehingga kompleksitas siklomatisnya :

$$
\mathrm{V}(\mathrm{G})=\mathbf{1 5 - 1 4 + 2 = 3}
$$

Basis set yang dihasilkan adalah:

$$
\begin{aligned}
& 1-2-3-4-5-6-7-9-10-11-12-13-14 \\
& 1-2-3-4-5-6-8-9-10-11-12 \\
& 1-2-3-4-5-6-7-8 \\
& 1-2-3-4-5-6-7-8-9-10-11-12-13- \\
& 14
\end{aligned}
$$

Ketika aplikasi dijalankan, terlihat bahwa salah satu basis set yang dihasilkan adalah:

$1-2-3-4-5-6-7-9-10-11-12-13-14$

dan terlihat simpul telah dieksekusi satu kali.

\begin{tabular}{|c|c|c|c|}
\hline No & Input & Output & Hasil \\
\hline 1 & $\begin{array}{l}\text { Tombol Menu } \\
\text { Angka }\end{array}$ & $\begin{array}{l}\text { Tampil } \\
\text { Menu } \\
\text { Angka }\end{array}$ & VALID \\
\hline 2 & $\begin{array}{l}\text { Tombol Menu } \\
\text { Huruf }\end{array}$ & $\begin{array}{l}\text { Tampil } \\
\text { Menu } \\
\text { Huruf }\end{array}$ & VALID \\
\hline 3 & $\begin{array}{l}\text { Tombol Menu } \\
\text { Membaca }\end{array}$ & $\begin{array}{l}\text { Tampil } \\
\text { Menu } \\
\text { Membaca }\end{array}$ & VALID \\
\hline 4 & $\begin{array}{l}\text { Tombol Menu } \\
\text { Berhitung }\end{array}$ & $\begin{array}{l}\text { Tampil } \\
\text { Menu } \\
\text { Berhitung }\end{array}$ & VALID \\
\hline 5 & $\begin{array}{l}\text { Tombol Menu } \\
\text { Latihan }\end{array}$ & $\begin{array}{l}\text { Tampil } \\
\text { Menu } \\
\text { Latihan }\end{array}$ & VALID \\
\hline 6 & $\begin{array}{l}\text { Tombol Menu } \\
\text { Bermain }\end{array}$ & $\begin{array}{l}\text { Tampil } \\
\text { Menu } \\
\text { Bermain }\end{array}$ & VALID \\
\hline
\end{tabular}
Berdasarkan ketentuan tersebut, sistem ini telah memenuhi syarat untuk di lanjutkan pada tahapan pengujian berikutnya yaitu pengujian blackbox.

\section{Pengujian Black Box}

Tabel 2.

Pengujian Black Box
Berdasarkan kedua teknik pengujian diatas, dapat dijelaskan bahwa media pembelajaran ini sudah memenuhi syarat dan siap digunakan.

Hal ini dapat dilihat dari hasil pengolahan lembar kuesioner yang penulis sebarkan kepada responden (guru dan siswa).

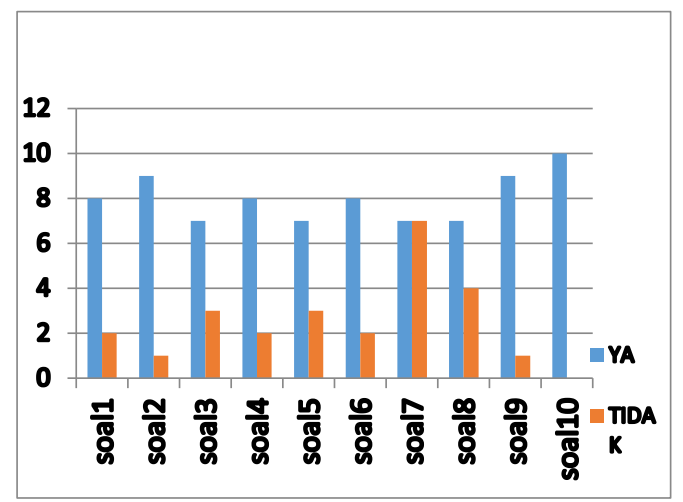

Gambar 16. Hasil pengolahan data kuesioner

\section{KESIMPULAN}

Berdasarkan pengamatan dari uraian dan penjelasan sub bab sebelumnya, maka penulis dapat mengambil kesimpulan antara lain:

1. Dalam pembuatan media pembelajaran berbasis android menjadi sangat menarik minat dan perhatian siswa, karena terdapat bentuk angka dan huruf dan bemacam-macam suara, dan gambar hal ini dapat di lihat dari hasil analisa kuesioner yang penulis dapatkan. Sebesar $80 \%$ menyatakan media pembelajaran ini mudah digunakan. $90 \%$ responden menyatakan responden menyukai aplikasi media pembelajaran pengenalan angka dan huruf berbasis animasi interaktif ini, $70 \%$ responden menyatakan belajar mengenal angka dan huruf itu menyenangkan.

2. Model pembelajaran pengenalan angka, huruf dan bentuk berbasis android ini dapat membantu proses pembelajaran dan meningkatkan minat belajar pada anak usia dini. Fasilitas yang tersedia dalam animasi interaktif ini antara lain materi tentang pengenalan warna, angka, huruf dan bentuk yang disediakan dalam bentuk gambar dan animasi, serta terdapat juga games berisi pertanyaan terkait materi pembelajaran mengenal warna, angka, huruf dan bentuk. Model pembelajaran pengenalan warna, angka, huruf dan bentuk dapat dipakai sebagai alat bantu mengajar baik oleh orang tua maupun guru. Media pembelajaran berbasis android lebih membuat anak sangat tertarik untuk mempelajarinya. 
3. Siswa juga dapat belajar sambil bermain, serta melatih mengenal angka dan huruf, dengan gambar yang beragam.

4. Pembuatan animasi angka dan huruf ini juga dapat membantu guru dalam melatih anak-anak di sekolah.

5. Pembuatan animasi angka dan huruf ini juga dapat melatih kreatifitas dan melatih daya ingat siswa-siswi.

\section{REFERENSI}

Khasanah, I. (2013). PEMBELAJARAN LOGIKA MATEMATIKA ANAK USIA DINI (USIA 4-5 TAHUN) DI TK IKAL BULOG JAKARTA TIMUR. PAUDIA: JURNAL PENELITIAN DALAM BIDANG PENDIDIKAN ANAK USIA DINI, 2(1 mei). https://doi.org/10.26877/paudia.v2i1 mei.368

Kurnianingtyas, L. Y., \& Nugroho, M. A. (2012). IMPLEMENTASI STRATEGI PEMBELAJARAN KOOPERATIF TEKNIK JIGSAW UNTUK MENINGKATKAN KEAKTIFAN BELAJAR AKUNTANSI PADA SISWA KELAS X AKUNTANSI 3 SMK NEGERI 7 YOGYAKARTA TAHUN AJARAN 2011/2012. Jurnal Pendidikan Akuntansi Indonesia, 10(1), 66-77. Retrieved from

https://journal.uny.ac.id/index.php/jpakun/artic le/view/922/733

Lestari. (2014). Pembuatan Media Pembelajaran Huruf Dan Angka Pada Taman Kanak Kanak Siwi Peni 1 Sragen. IJNS - Indonesian Journal on Networking and Security, 3(1). https://doi.org/10.1123/IJNS.V3I1.119

Ridho, R., Markhamah, \& Darsinah. (2015). Pengelolaan pembelajaran pendidikan anak usia dini (PAUD) di kb "cerdas" kecamatan sukorejo kabupaten kendal. Jurnal Penelitian Humaniora.

Setiani,Dewi,Santoso Sigit, S. (2016). PENGEMBANGAN BAHAN AJAR INSTA ACCOUNTING BERBASIS MULTIMEDIA INTERAKTIF UNTUK MENINGKATKAN MOTIVASI BELAJAR SISWA SMK. Tata Arta, 2(2). Retrieved from http://garuda.ristekdikti.go.id/journal/article/58 5693

Sidik, N. A. (2017). ANIMASI INTERAKTIF PENGETAHUAN DASAR BAHASA DAN MATEMATIKA BERBASIS MULTIMEDIA. Techno Nusa Mandiri, 14(2), 83-90. Retrieved from

http://ejournal.nusamandiri.ac.id/ejurnal/index. php/techno/article/view/488

Waskito, D. (2017). Media Pembelajaran Interaktif Matematika Bagi Sekolah Dasar Kelas 6 Berbasis Multimedia. Speed - Sentra Penelitian Engineering Dan Edukasi, 9(1), 20. Retrieved from http://ijns.org/journal/index.php/speed/article/ view/1296/1284

Wiyarti, Y., \& Nugroho, G. K. (2013). PEMBANGUNAN MEDIA PEMBELAJARAN ALAT TRANSPORTASI DAN RAMBU-RAMBU LALU LINTAS PADA TAMAN KANAK-KANAK PERTIWI 1 PLUMBUNGAN KARANGMALANG SRAGEN. EPUB - MEDIA INTERAKTIF, 1(1), 40. Retrieved from http://www.epub.tiunsa.org/index.php/MediaI nteraktif/article/view/6

Yuniati, N., Purnama, B., \& Nugroho, G. (2012). Pembuatan Media Pembelajaran Interaktif Ilmu Pengetahuan Alam Pada Sekolah Dasar Negeri Kroyo 1 Sragen. Speed-Sentra Penelitian Engineering, 3(4), 25-29. Retrieved from

http://www.ijns.org/journal/index.php/speed/ar ticle/view/866

\section{PROFIL PENULIS}

Sidik,M.Kom Lahir di Jakarta tanggal 12 Juli 1979. Saat ini bekerja sebagai staf pengajar (dosen) pada program studi Teknik Informatika STMIK Nusa Mandiri. Mengambil gelar Magister Komputer pada STMIK Nusa Mandiri jurusan Ilmu Komputer dan lulus tahun 2011. Aktif mengikuti pelatihan-pelatihan dan seminar yang menunjang dalam hal penelitian-penelitian. Menulis beberapa buku ajar dan jurnal ilmiah. Email: sidik.sdk@nusamandiri.ac.id

\section{Riwayat Pendidikan}

- Program Pasca Sarjana STMIK Nusa Mandiri Jakarta (2011)

- Strata Satu STMIK Nusa Mandiri Jakarta (2005)

- Diploma III Akademi Manajemen Informatika Bina Sarana Informatika (AMIK BSI) Jakarta (2001)

- Sekolah Menengah Umum Negeri 75 Jakarta (1998)

- Sekolah Menengah Pertama Negeri I Prembun (Jawa Tengah) (1995) 
- Sekolah Dasar Negeri Ungaran I- Jawa Tengah (1992)

Nama lengkap MuhamadFajar Syahroni, Tempat \& Tanggal lahir Bogor, 29 April 1990. Saat ini bertempat tinggal di Jl.Pekapuran Rt.01 Rw.01 No 04 Kel.Sukatani Kec.Tapos Kota Depok. Menempuh pendidikan terakhir di STMIK Nusa Mandiri program studi Teknik Informatika.

\section{Riwayat Pendidikan:}

1. MI Al futuhaat Al Attasiyah Depok, lulus tahun 2001

2. SMP Taruna Bhakti Depok, lulus tahun 2005

3. SMK Taruna Bhakti Depok, lulus tahun 2008

4. AMIK Bina Sarana Informatika Depok, lulus tahun 2012 